\title{
Work-Family And Sports: When Even Millionaire Athletes Need Employer Help To Balance Work And Family
}

Scott J. Behson, (Email: Behson@fdu.edu), Fairleigh Dickinson University

\begin{abstract}
Three cases in which professional athletes required workplace accommodation to balance work and family are presented, including analysis of each case based on the current work-family literature.
\end{abstract}

\section{INTRODUCTION}

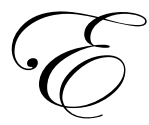

ight years ago, I wrote an article that appeared in April 1999 issue of The Industrial/ Organizational Psychologist, 36 (4), 51-56. It examined how three major sports figures found a way to balance their work and family commitments with the help of their employers through informal arrangements.

The present article provides an update of each of these cases, and applies recent research findings as a lens for interpreting them. Researching these events has led me to the realization that even millionaire athletes struggle with work and family issues, and that they and their employers make minor, and sometimes major, accommodations in order to balance both work and family. If these people, with all of their financial resources, need help, what does this imply for employees with more rigid jobs and less financial resources?

\section{LITERATURE REVIEW}

The drastic economic and societal changes that have taken place over the past few decades have made conflict between work and family roles a major source of stress for many employees. In keeping with its standing as a pressing social issue, the study of work-family conflict has gathered great momentum in the past two decades.

Much of the organizational research into work-family issues has indicated that employers can play a vital role in helping their employees balance the often competing demands of work and family (e.g., Batt \& Valcour, 2003; LaPierre \& Allen, 2006). In particular, evidence is beginning to accumulate that family-friendly human resource policies, such as flextime, telecommuting, day-care services, parental leave, and job-sharing, can provide considerable benefit to both the employee and the organization. Employees can gain greater discretion over the use of their time and financial resources, and the organization can gain in terms of decreased voluntary absenteeism, decreased turnover, improved employee satisfaction, improved public relations, and an improved ability to attract and retain qualified workers in a tight labor market, especially for highly skilled employees (e.g., Bond, Galinsky \& Swanberg, 1998; Grover \& Crooker, 1995). However, it is also noted that many employees do not avail themselves of formal work-life policies, for fear that it would negatively affect their careers and management's perceptions of them (Behson, 2002; Kirby \& Krone, 2002)

As a result, the importance of work-family culture has also emerged as a major research trend (e.g., Allen, 2001; Clark, 2001; Thompson, Beauvais \& Lyness, 1999). There is growing evidence that employees' ability to navigate their work and family conflicts resides not just in formal policy, but in the underlying assumptions of companies and their managers. Several researchers have found that perceptions of family-friendly cultures reduces stress and strain, and enables more employees to make use of informal ways to balance their work and family lives (e.g., Behson, 2002, 2005). 
Now that many businesses are recognizing that family-friendly policies and cultures can be important for the bottom line, we are beginning to see examples of successful programs being instituted in a wide variety of industries, ranging from human services, manufacturing, and electronics (e.g., Fortune magazine's annual survey of the "Top 100 Companies to Work For"). If you look closely enough, some of these practices have even begun to emerge within the ultra-competitive industry of professional sports.

If the connection between work-family issues and professional sports does not seem obvious to you, you are not alone. There are three reasons why I began to think of these issues together. First, I conducted my dissertation (and subsequent) research on how employees use informal work arrangements to balance their work and their family lives, and I have been doing a considerable amount of reading into how fathers, in particular, manage the work-family pressures they face. Second, I am a complete sports fanatic. Third, the sports industry is highly competitive, very macho, and very results-oriented. When wins and losses can mean hundreds of millions of dollars, there is very intense pressure to be single-mindedly focused on work and a professional ethic that rewards incredibly long work hours. In this environment, it would be logical to see workplace cultures that are hostile to work-family balance concerns. Thus, instances in which players, teams, and organizations support life balance at the potential risk of losing are quite notable.

While avidly following major pro sports for the past several years, three sports-and-family related events from 1998-1999 stuck out in my mind. In this article, I provide updates on these stories, using more recent research as a way to explain and interpret these cases. Finally, I report what, if any, long-term benefit the employers received based on their flexibility.

\section{ON-SITE DAY CARE WITH MARK MCGWIRE}

Mark McGwire's achievements during the 1998 baseball season are nothing short of awe-inspiring. His 70 home runs obliterated the late Roger Maris' seemingly unbreakable single season record of 61 set back in 1961. Accordingly, McGwire, the first baseman of the St. Louis Cardinals, has been named both Baseball Player of the Year and Male Athlete of the Year by the Associated Press, and was named co-Sportsman of the Year by Sports Illustrated. The magnitude of McGwire's personal achievements, combined with his personable and gregarious demeanor, allowed the sports fans of America to learn a lot about Mr. McGwire's life beyond baseball.

Mr. McGwire is a single, divorced dad, who shares custody of his then 10-year old son, Matthew. McGwire has stated in several interviews that his favorite aspect of his historic home run chase was sharing the experience with his son, who accompanied McGwire in the dugout for most of the games leading up to his recordbreaking 62 nd homer.

There are several enduring images from the night that McGwire broke Maris' record: his swing, the roar of the crowd, his excited trot around the bases, the congratulations offered to him by the opposing team, his embrace of Sammy Sosa of the Chicago Cubs (who also pursued and surpassed Maris' record), the respect McGwire showed to Roger Maris' family, and the enthusiastic greeting his teammates gave him as he reached home plate. However, the defining moment of that night was when McGwire hugged and lifted his son, sharing and savoring the moment with him.

McGwire's son, however, would not have been able to stay in the St. Louis dugout for all those evenings if the Cardinals did not have an informal on-site day care policy, at least for the older children of its most valued employees. If McGwire could not have taken his son with him to work, he would have had to arrange some sort of child care since McGwire's ex-wife lives in another city.

It would be a stretch to say that McGwire's performance would have suffered if Matthew was not by his side. However, it is possible to state that this team day-care policy, as informal as it was, did reduce a major stressor in his life, allowing him to focus on the task at hand. Further, McGwire went on record several years ago as saying that he wished to remain a Cardinal for the remainder of his career, and he even took less money to play for this team because of how well the organization treated him. 
Allowing the children of players to accompany their dads' to work is apparently a common practice among many major league ballclubs. Interviews with second generation baseball players, such as Brett Boone, Ken Griffey Jr., and Todd Hundley, reveal that the time that they spent in their dads' workplace was instrumental in their ability to handle life in the major leagues later on.

It is refreshing to see, that in as competitive an industry as Major League Baseball, that team ownership and management have informally arranged for their players to spend part of their time at work with their families. While the connection between this informal on-site day care policy and performance is tenuous, it has, at least, allowed for baseball players and their children to share some incredible baseball moments and spend quality time together.

\section{Update:}

Mark McGwire had another stellar season in 1999, but suffered an array of injuries in 2000 and 2001. He remained a St. Louis Cardinal until his retirement after the 2001 season. He was a local hero and remained very closely associated with the organization- and had every intention on having a lifetime relationship with the teamuntil allegations and evidence of his use of illegal performance-enhancing drugs surfaced over the past two years. Most notably, McGwire sidestepped questions posed to him by a Congressional panel that was investigating the use of performance-enhancing drugs in baseball. These televised remarks left him a baseball pariah, and even prevented him from being elected to Baseball's Hall of Fame, despite historical accomplishments and career accomplishments worthy of Hall of Fame induction.

Thus, while the St. Louis cardinals and McGwire shared a positive working relationship that was conducive to long-term partnership, the fruits of this relationship never blossomed because of the public scrutiny caused by his potentially illegal and certainly immoral behavior.

It remains common to allow children of players to accompany their dads in the locker rooms and on the field before games. However, this is often less of a work-family accommodation than it is a way to keep a star employee happy by providing a thrilling opportunity for their kids.

\section{PARENTAL LEAVE WITH JOHN OLERUD}

John Olerud was the first baseman for the New York Mets from 1996-2000. While he was not a superstar, he was widely respected as a solid player and good teammate. His career highlights include winning two World Series championships with the Toronto Blue Jays, winning three Gold Glove Awards (given to the best defensive player at each position), and winning the batting title in 1993. Mr. Olerud was an important part of the 1998 New York Mets team which contended for the last National League playoff spot until the final game of that season.

While the Mets were embroiled in their race against the Chicago Cubs and the San Francisco Giants, Mr. Olerud's wife, Kelly, went into labor with the couple's first child, Garrett. The Mets management allowed Mr. Olerud and his impressive .343 batting average to leave the team to participate in Garrett's birth and to spend as much time away from the team as he felt he needed. In all, Olerud missed three games (five days) for the Mets during this most critical time of the season. "The practice across baseball is that you miss three games... It's one of those understood things," said Mets General Manager, Steve Phillips. The Mets' manager, Bobby Valentine, did not (publicly, at least) put any pressure on Olerud to curtail his paternity leave. He was quoted in the New York Times as supportive of Olerud, "When it's proper, he will be here. John makes good decisions." He also added, "It is the single greatest event in anyone's life. There is nothing more miraculous or special than the birth of a child."

Both Bobby Valentine and Mets' assistant coach Cookie Rojas observed that times have changed, and, in their opinion, have changed for the better. Rojas stated that he had missed the births of three of his four children while playing baseball, and Valentine recalled all of the bureaucracy he had to go through when his child was born fifteen years ago, when Valentine was an assistant coach for the Mets. 
Although the Mets are clearly a better team with Olerud in the middle of their batting order, the team fared well during Olerud's absence. From the time he left the team until he returned, the Mets stayed even with the Chicago Cubs for the last playoff spot. In addition, Olerud's performance did not suffer as a result of his absence. In fact, he subsequently raised his batting average to .354 and ended the season with the second-highest batting average in the National League. It wasn't until the final week of the season, well after Olerud returned, that the Mets played poorly, and lost out on the final playoff spot to the Chicago Cubs.

It appears to be informal league policy that baseball players can miss up to three games as a sort of makeshift paternity leave at the birth of a child. This is comparable to Pleck's (1993) description of how fathers informally manage the boundaries between work and family, and how organizations provide certain avenues for these informal accommodations.

The Mets allowed Mr. Olerud the discretion to spend time with his wife and newborn child during the most crucial part of the season, where one small mistake could cost the team millions of dollars in playoff revenues. Even though the team failed to reach the playoffs, the informal paternity leave policy did not appear to hurt either Olerud's or his team's performance. It remains to be seen, however, whether teams realize a long-term benefits to their consideration of the players' parental needs through reduced turnover, a better reputation among potential freeagents, and reciprocated loyalty when players' next contracts are negotiated.

\section{Update:}

John Olerud, who was born in and always maintained his family's residence in Seattle, Washington, left the Mets when his contract expired before the 2000 season. Thus, despite the Mets' willingness to be flexible, he only played one more season for New York after his child's birth.

There are very few times in a professional athlete's life where he has control over where he works. In fact, baseball players have no control over this until after their sixth full year in the major leagues (often after several years in the minors). Olerud used his opportunity to join a team that presented him with the greatest ability to balance work and family- his hometown Seattle Mariners. After leaving the Mets, he played with the Mariners for four seasons, and retired in 2005.

We increasingly see players use their free-agency freedom to balance their work and family lives. Examples include the recent decisions of such players as Randy Johnson, Brian Giles, and Tim Wakefield.

Further, although there is nothing in the Major League Baseball collective bargaining agreement to guarantee this right, it has become standard practice that players are allowed a few days off upon the birth of a child. Most notable is the recent (June 2006) case of Cesar Izturis, then a backup infielder for the LA Dodgers. He was originally cleared to leave the team for 48 hours to be at the birth of his child. However, he was given an extra three days away from the team as his wife had a difficult delivery and needed more time to re cover.

\section{JOB-SHARING WITH JIMMY JOHNSON}

Jimmy Johnson earned a reputation as a brilliant, intense, and very dedicated football coach who worked as hard as anyone to prepare his team for battle each Sunday. He won a National Collegiate Championship with the University of Miami in 1987 and two Super Bowl rings with the Dallas Cowboys in 1992 and 1993. From 19961999, he was the coach of the Miami Dolphins, and he guided them to the playoffs in 3 of his 4 years as coach.

Coach Johnson has admitted in several televised and printed interviews that he often logs sixteen-hour days when preparing for his weekly opponents. He is a self-admitted workaholic, and has acknowledged that his family life has suffered for it. In fact, in one radio interview several years ago, he admitted that he didn't celebrate his sons' birthdays, and that it seemed like he only saw his wife while attending social events and making public appearances. 
However, towards the end of the 1998 season, Coach Johnson's mother died, and Johnson missed the wake because he was on the field coaching the Dolphins the day after her death. This experience seemed to shift his priorities. Shortly afterwards, he publicly resolved to spend more time with his fiancé, his sons, and his ailing father, who, at the time, was battling prostate cancer.

On January 12, 1999, ESPN reported that Coach Johnson resigned as head coach of the Miami Dolphins, citing the desire to spend more time with family. "When mother passed away, it opened up my eyes and made me realize I had to spend more time with people I cared about." However, the next day, after a meeting with Dolphins' owner Wayne Huizenga, president Eddie Jones, star quarterback Dan Marino, and other Dolphin officials, Coach Johnson announced that he, in fact, was not resigning. As part of the arrangement to help him stay on as head coach, Dave Wannstedt, the former head coach of the Chicago Bears and former Dallas Cowboys Defensive Coordinator under Johnson, was hired to fully share the head coaching duties with Johnson, under the somewhat paradoxical title of "Assistant Head Coach".

The rationale for such a unique personnel decision was that both Johnson and Wannstedt would share the position of Head Football Coach, with Johnson as the primary of the two head coaches. In his televised press conference on January 13, 1998, Johnson wept while talking about attending his mother's funeral but missing her wake because of work. Johnson also explained that, because of his desire to spend more time on his family and personal life, he needed to make an arrangement to create more free time for himself. "There's a time when you pull back and you say, 'Be with people you care about. Don't shortchange them.' That's what I plan on doing.”

Such a unique coaching arrangement is not without its risks. While one theory states that two heads are better than one, the predominant opinion in sports is that that the players need to have clear lines of authority with one man who is both fully in charge and ultimately accountable for team performance. In any case, Mr. Huizenga and the Miami Dolphins organization has exhibited flexible thinking and individualized consideration, or what Hall (1990) would refer to as a "less rigid form of flexibility." Such an approach often seems to be the best solution to alleviating workers' work-family conflicts.

It would have been much easier for the Dolphins to tell Johnson either that they needed him to work the typical hours of a head football coach- often more than 80 hours a week- or that they would find someone else who would. However, by being creative and working for a solution that satisfied this star employee's personal needs, the Dolphins were able to retain Johnson's commanding presence and coaching genius. Other potential benefits of this decision for the Dolphins included: (a) avoiding the expense associated with hiring a new Head Coach in a very competitive labor market (there were five other coaching vacancies at the time), (b) reducing turnover among the current Assistant Coaches who would probably be replaced by a new Head Coach, (c) planning for executive succession as Wannstedt would be groomed for the Head Coach position when Johnson eventually does retire, and (d) avoiding a possible drop-off in performance while the players adjusted to new leadership.

\section{Update:}

Coach Johnson retired after the 1999-2000 season, after only one year in his job-sharing arrangement. He has since remained in football, but in a far less demanding role as a television analyst.

Dave Wannstedt became head coach of the Miami Dolphins in 2000, and remained in this position for the next five seasons. Thus, despite losing Johnson just a year after accommodating him, the Dolphins were able to use job-sharing as a way to ensure a smooth succession, without the turmoil and turnover that usually accompanies a change in head coach. The transition from Johnson to Wannstedt went very well. Under Wannstedt, the Dolphins made the playoffs in 2001 and 2002, and had a winning record in 2003 before things started going badly in 2004. In fact, in the nine seasons under these two coaches, the Dolphins made the payoffs six times and only had one losing season. All in all, the Dolphins were spared a large-scale change at the top of their coaching staff for several years after their coach retired, and, although they never won a championship during this time, they enjoyed a period of sustained success. 
In the two plus years since replacing Wannstedt, the Dolphins have experienced considerable turmoil. Former LSU coach Nick Saban was hired in 2005 to much fanfare, but was unsuccessful as a coach, failing to make the playoffs in either of his seasons, despite the Dolphins being tabbed Sports Illustrated's Super Bowl pick in 2006. $\mathrm{He}$ also alienated his bosses, the press, fans and players. The Dolphins are now transitioning to their fourth coach in four years, this time to first-time head coach, Cam Cameron.

To my knowledge no other major sports team has experimented with job-sharing or has attenuated its expectations for coaches' work hours. However, the period of relative success the Dolphins experienced with this arrangement (especially considering the problems they've experienced when they paid less attention to long-term succession planning) provides some evidence that this arrangement could work for other teams or in other industries.

\section{ANALYSIS}

Professional athletes often get a bad reputation for being careless, absentee, or deadbeat fathers who are constantly on the road, leaving their wives and children to get by as best they can without them. While this perception may be true for some athletes, these three stories opened my eyes to a different side of professional athletics. Many athletes are very dedicated parents who, just like the rest of us, make decisions to alter their work lives in order to accommodate their family responsibilities.

All three of these examples illustrate the widespread importance of work-family issues, and each story contains lessons for management research and practice. In the Mark McGwire story, the St. Louis Cardinals probably did not even realize that they were being "family-friendly". However, the climate of the team was conducive to work-family balance (Allen, 2001; Clark, 2001; Thompson, et al., 1999), and allowed for the emergence of informal work-family arrangements by their employees (Behson, 2002).

The John Olerud story demonstrates that, while fathers tend to take much less formal parental leave than their female counterparts (Galinsky, et al., 1998; Hall, 1990), many are creative in utilizing available time off and other pre-existing sources of workplace flexibility in order to create makeshift paternity leaves for themselves (Pleck, 1993).

Finally, the Jimmy Johnson story shows that formal workplace accommodations, such as job-sharing, which are traditionally seen as appropriate only for lower-level jobs, can be applied to managerial positions. The success of this arrangement may provide justification for businesses in other industries to consider pushing workfamily accommodations up the corporate ladder.

In conclusion, these stories provide anecdotal evidence that flexible thinking and informal arrangements can be the key to alleviating some of the stress associated with work and family issues. McGwire, Olerud and Johnson show that even millionaire superstar athletes struggle with work and family pressures, and can use assistance from their employers in alleviating this source of stress. If the All-Time Home-Run King, a batting champion, and a Super Bowl coach need assistance from their employers to help them balance work and family, it makes a strong case for the near-universal importance of work-family balance in today's business environment.

\section{REFERENCES}

1. Allen, T.D. (2001). Family-supportive work environments: The role of organizational perceptions. Journal of Vocational Behavior, 58, 414-435.

2. Associated Press. (1999, January 14). Jimmy stays as Miami coach. Available: Espn.go.com/nfl/news/1999/990113/01044119.html.

3. Batt, R. \& Valcour, P.M. (2003). Human resources practices as predictors of work-family outcomes and employee turnover. Industrial Relations, 42, 189-220.

4. Behson, S.J. (2005). The Relative Contribution of Formal and Informal Organizational Work-Family Support. Journal of Vocational Behavior, 66, 487-500. 
5. Behson, S.J. (2002). Coping with family-to-work conflict: The role of informal work accommodations to family. Journal of Occupational Health Psychology, 7, 324-341.

6. Behson, S.J. (April 1999). Work-Family Comes to the World of Sports. The Industrial/ Organizational Psychologist, 36 (4), 51-56.

7. Bond, J. T., Galinsky, E., \& Swanberg, J. E. (1998). The 1997 National Study of the Changing Workplace. New York: Families and Work Institute.

8. Clark, S.C. (2001). Work Cultures and Work/Family Balance. Journal of Vocational Behavior, 58, 348365 .

9. Curry, J. (1998, September 9). A reluctant home-run hitter, a reluctant hero: Mark David McGwire. The New York Times. p. D3.

10. Diamos, J. (1998, September 11). With suspense over, team waits for Olerud. The New York Times, p. D2.

11. Grover, S.L. \& Crooker, K.J. (1995). Who appreciates family-responsive human resource policies: The impact of family-friendly policies on the organizational attachment of parents and non-parents. Personnel Psychology, 48, 271-288.

12. Hall, D. T. (1990). Promoting work/family balance: An organization change approach. Organizational Dynamics, 18, 3, 5-18.

13. Kirby, E.L. \& Krone, K.J. (2003). The policy exists but you can't really use it: Communication and the structuration of work-family policies. Journal of Applied Communication Research, 30, 50-77.

14. LaPierre, L.M. \& Allen, T.D. (2006). Work-supportive family, family supportive supervision, use of organizational benefits, and problem-focused coping: Implications for work-family conflict and employee well-being. Journal of Occupational Health Psychology, 11, 169-81.

15. Mets are waiting for Olerud. (1998, September 12). The New York Times, p. D5.

16. Pleck, J. H. (1993). Are family-supportive employer policies relevant to men? In Hood, J. C. (Ed.) Men, Work, and Family. Newbury Park, CA: Sage Publications.

17. Thompson, C. A., Beauvais, L. L., \& Lyness, K. S. (1999). When work-family benefits are not enough: The influence of work-family culture on benefit utilization, organizational attachment, and work-family conflict. Journal of Vocational Behavior, 54, 392-415.

18. Wannstedt joins Johnson in Miami. (1999, January 14). Sports Ticker Article. Available: Nfl.com/dolphins/news/990114johnson.html. 
NOTES 